\title{
Extensive Phenotypic Diversity among South Chinese Dogs
}

\author{
Marie-Dominique Crapon de Caprona ${ }^{1}$ and Peter Savolainen ${ }^{2}$ \\ ${ }^{1}$ College of Liberal Arts and Sciences, University of Iowa, 143 Biology Building, Iowa City, IA 52242, USA \\ ${ }^{2}$ Division of Gene Technology, School of Biotechnology, Science for Life Laboratory, KTH Royal Institute of Technology, \\ 17165 Solna, Sweden \\ Correspondence should be addressed to Peter Savolainen; savo@kth.se
}

Received 2 June 2012; Accepted 20 June 2012

Academic Editors: J. M. Eirin-Lopez, G. Glöckner, M. L. Hale, and J. Trueman

Copyright (c) 2013 M.-D. Crapon de Caprona and P. Savolainen. This is an open access article distributed under the Creative Commons Attribution License, which permits unrestricted use, distribution, and reproduction in any medium, provided the original work is properly cited.

\begin{abstract}
We describe here a broad diversity in phenotype among dogs in southern China's rural areas, previously relatively unknown outside of China. These dogs display a much broader spectrum of diversity than is observed for the Indian Pariah Dog and the Australian Dingo, which are of a more uniform type and popularly thought to be typical for South Asian dogs and to represent the primitive morphology of the earliest domestic dogs. We show here that the village dog population of southern China harbors a broad diversity of morphological features, for color, body structure and size, coat texture, ear, and tail set, that are otherwise typically associated with the wide variety of Western dog breeds and assumed to be the result of intense selective breeding. The diversity of southern China's dogs is cast in the light of mtDNA and Y-chromosome DNA studies showing that the genetic diversity is distinctly higher in southern East Asia than in the rest of the world, indicating that this was the geographical origins of today's dog. These data suggest that the diverse morphologies of European dogs may have been formed from genetic "building blocks" still present in the dog population of rural southern China.
\end{abstract}

\section{Introduction}

Recent publications have shown that dogs in southern East Asia (China south of the Yangtze River and southeast Asia) harbor practically the full genetic diversity for mitochondrial DNA (mtDNA) [1, 2] as well as Y-chromosomal DNA [3], while all other indigenous dog populations across the world harbor just a subset of the gene pool found in southern East Asia (Figure 1). Consequently, the genetic diversity for these markers is distinctly higher for dogs in southern East Asia than in all other dog populations across the world. Most noticeably, in the universal dog gene pool there are 10 principal genetic groups of mtDNA, and all these groups have been found in southern East Asia, while only subsets of this gene pool were found in other regions, for example, Europe (4 of the 10 groups), Southwest Asia (5), and north China (5). This gives a strong indication that today's Domestic Dog (Canis familiaris) originated from wolves in southern Eastern Asia, thus suggesting a region not previously thought to be the place of dog origins. The previously most prominent theories about dog origins were based on the archaeological record and proposed that dogs originated from either Southwest Asia or Europe, or from several separate regions, since the earliest reasonably firm evidence of domestic dogs are from Southwest Asia $[4,5]$ and Europe $[6,7]$. However, interpretations of the archaeological record are problematic because there is great difficulty in distinguishing Dog from Wolf in the paleontological material and because archaeological research on dogs is lacking in many parts of the world. There is also the possibility that some lineages of tamed wolves did not survive until today [8]. Furthermore, in a recent study, genomewide SNP variation was interpreted as indicating that dogs originated in Southwest Asia [9]. However, samples from southern East Asia were not included in this study, implying that if this region was actually the region where dogs originated, this would have gone undetected $[2,10]$.

It is perhaps because of the previous lack of indications that the dog originated in southern East Asia that little interest has been focused on dogs from this region. It is 


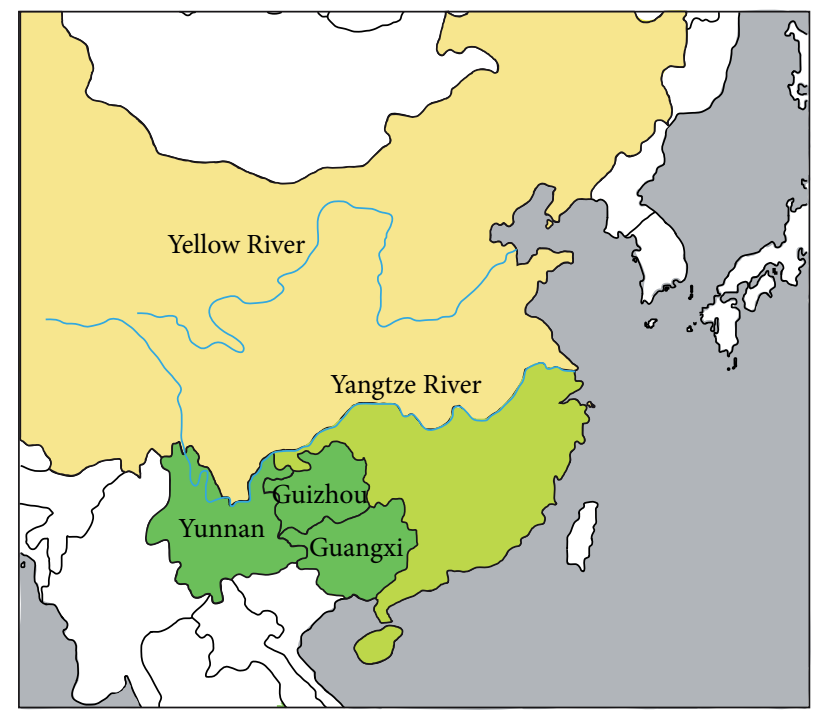

FIGURE 1: Southern China (China south of the Yangtze River) is indicated in green, the three provinces specifically surveyed in this study (Yunnan, Guizhou, and Guangxi) in darker green, and the remaining part in light green. The rest of China is indicated in beige.

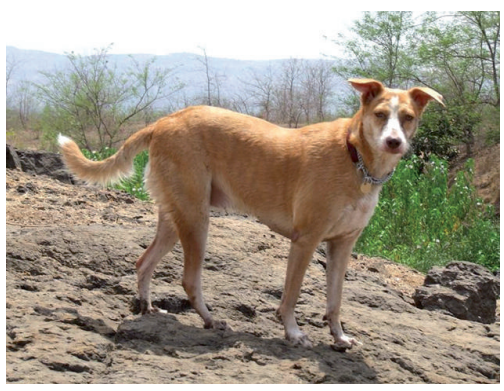

(a)

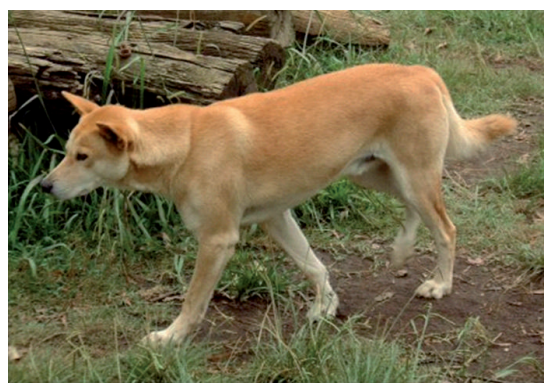

(b)

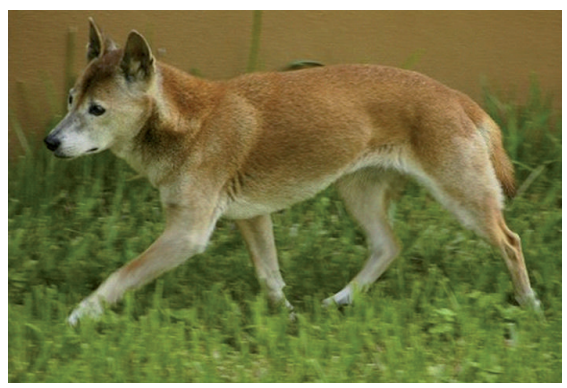

(c)

Figure 2: (a) Indian Pariah, (b) Australian Dingo, and (c) New Guinea Singing Dog. (Yajnesh Shetty, Alan Wilton, and Valerie Abbott, respectively).

generally assumed in the Western World that dogs in South Asia are uniform in appearance, being of medium size, reddish fawn, and with prick or half erect ears and bushy tail, thus resembling the Indian Pariah Dog, the Australian Dingo (although there is some variation in coat colors and coat length in both), or the New Guinea Singing Dog (Figure 2). Furthermore, because the Dingo and New Guinea Singing Dog populations developed several thousand years ago [11, 12], their morphology is considered to be "primitive" and is argued to be similar to that of the earliest domestic dogs $[11,13,14]$. The large range of different morphological traits found among Western dog breeds would therefore primarily be the result of more recent intense selective breeding and possibly of crossbreeding with local wolf in Europe.

However, as presented in this study, dogs in the rural parts of southern China display a wide diversity of phenotypes, with clear differences in size, structure, coat texture and color, ear-set, and tail carriage. Thus, these dogs, which have not been the subject of the kind of intense selective breeding based on exterior morphology practiced in the Western World display morphological features which are typically used to distinguish between dog breeds in the various canine registries worldwide.

There are some 350 breeds and varieties recognized by the largest Western Canine Society, the Fédération Cynologique Internationale (FCI). Among these, only a single breed, the Sharpei, is considered to have an origin from southern China, and 4 other breeds are considered to have other Chinese origins: the Chinese Crested dog (2 varieties, hairless or powderpuff), the Chow Chow, the Pekingese, and the Pug (Ba Ge Quan) (see Supplementary Material available online at doi: http://dx.doi.org/10.5402/2013/621836). Five additional breeds are recognized as Tibetan: the Do Kyi (Tibetan Mastiff), the Lhasa Apso, the Shih Tzu, the Tibetan Spaniel, and the Tibetan Terrier. One additional Chinese breed, the Taiwan Gou, is currently provisional within the FCI, another is recognized by the Chinese Kennel Club, the Xiaxi Quan (Figure 3). Within FCI, the breeds are separated according to phenotype and function in to 10 groups. Chinese and Tibetan breeds are found only in 3 groups, in Group 2 (Section 2: Molossoid Breeds: Shar Pei; Mastiff type: Tibetan Mastiff), 5 (Spitz and primitive types, section 5: Chow Chow), and 9 


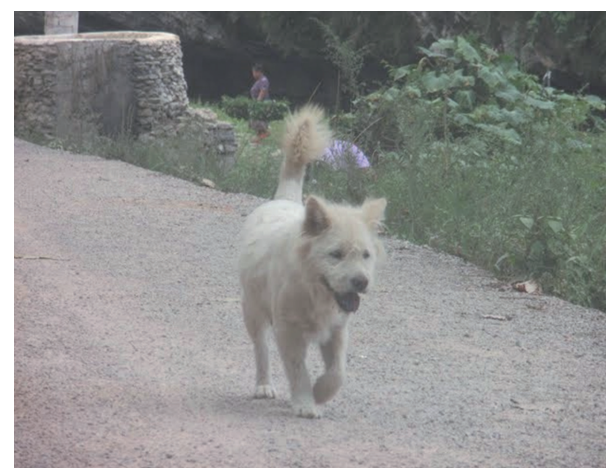

Figure 3: Wire-haired "Xiasi Quan" in the small horned Miao village of Boji, southern China. (P. Touret). The breed, which is named after the village of Xiasi, prefecture of Kaiili, is now accepted in most Chinese dog shows, if not by the Fédération Cynologique Internationale.

(Companion and Toy dogs: section 5: Tibetan Terrier, Tibetan Spaniel, Shih Tzu, and Lhasa Apso; section 8: Pekingese, section 11: Pug).

In stark contrast, European dog breeds dominate in terms of numbers and variety of phenotypes and are represented in all 10 FCI groups. If the dogs in southern East Asia would generally have the limited morphological diversity of Dingoes and Pariah dogs, it may therefore seem surprising that the genetic basis for the immense morphological variation found among Western dog breeds would have originated from southern Eastern Asia, as indicated by mtDNA and Ychromosomal DNA data [1-3].

However, a closer look at the indigenous dogs in southern China reveals that they display a broader spectrum of phenotypes than is generally known in the West, and some form distinct populations not recognized by Western Canine Societies-although some are now allowed in Chinese dog shows (such as the Xiasi Quan, Figure 3).

Many of the features found in European breed dogs could possibly have derived from similar features found today among southern China's dogs. Because so little is known in the West about the variety of phenotypes these dogs display, we present here a photographic study of the diversity in dogs of this region.

\section{Materials and Methods}

The dogs were photographed in the summers of 2009 and 2010 in villages of the south Chinese provinces of Guangxi, Guizhou, and Yunnan (Figure 1). The dogs were kept by the ethnic groups named black Miaos, small horned Miaos, and Gejia. These groups are linguistically related peoples in southwest China, the Miaos referred to in Chinese as "small horned" or "long-horned" Miaos depending on the length of the horns of their headpieces, or black, white, red, and so forth, depending on the most characteristic color of the women's clothes.

All dogs belonged to a specific home; none was stray. Chinese indigenous village dogs are generally well looked after because of their usefulness, be it as a hunting dog, a guard dog or as a source of food [15].

Although it is not possible to ascertain what happened in the distant past, extensive crossbreeding with European dogs, which could explain the morphological diversity, is unlikely since the dogs were traditionally bred in rural areas located far from large towns, and because no such influence is known.

\section{Results}

The phenotypes of southern China's dogs represent a wide diversity, which adds to the already diverse Chinese breeds recognized by the FCI. Their variety is shown as follows:

(1) in color-solid white, black, pale cream, fawn with or without black mask, brindle, black and tan, and particolored (Figure 4);

(2) in structure and size-from short legged to long legged, small-to-medium-sized to tall and powerful (Figure 5);

(3) in coat texture-smooth coated, wire haired, curly and long haired (Figure 6);

(4) in ear set-prick ears, half-erect ears, and lop ears (Figure 6);

(5) in tail set-curled and carried high, short, straight, carried low or high (Figure 7).

Thus, among traditionally bred dogs from southern China we find a much broader range of phenotypes, varying in size, color, coat texture, ear, and tail set, than is found in the Indian Pariah, Australian Dingo or New Guinea Singing Dog populations. It is noticeable that many of these phenotypic features are what one could perceive as "building blocks" from which the broad morphological spectrum of European breeds may have derived.

Several different distinct populations, land races or "breeds" (even if they are not yet recognized by Canine Registries) in the sense that their phenotype is stable and passed on from generation to generation exist in different parts of southern China and are found in distinct locations, for example,

(i) the wirehaired "Xiasi Quan", named after the village of Xiasi, prefecture of Kaiili (Figure 3);

(ii) the white powerful dogs from the Matang village of the Gejia people (Guizhou) (Figure 5; picture 7);

(iii) the "Pig-Dog" of the minority Dong (small town of Yangxi (Guangxi) (Figure 5; picture 5, dog on right);

(iv) the hunting dog of the Guangxi region (Figure 5; picture 5, dog on left);

(v) Yunnan's “Tu Gou” (Figure 5; picture 8);

(vi) Guizhou's Spitz type (Figure 4, picture 9) black Miao village of Biasha. 


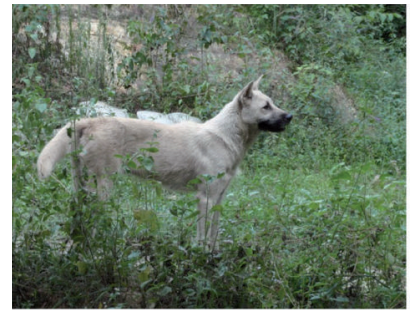

1. Pale cream black mask

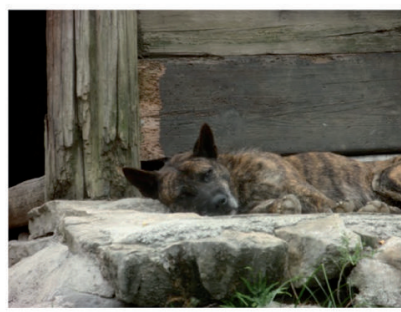

4. Red brindle

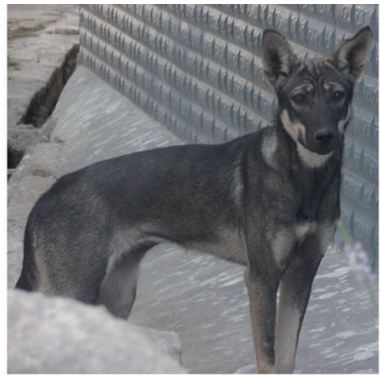

7. Grizzle with black mask, Yunnan

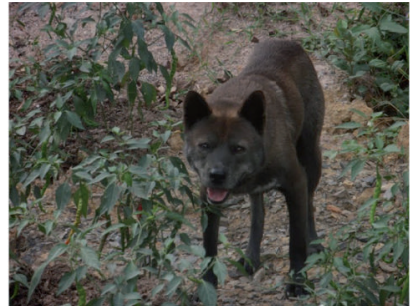

2. Chocolate brown

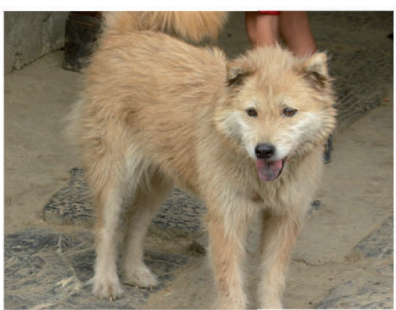

5. Red fawn

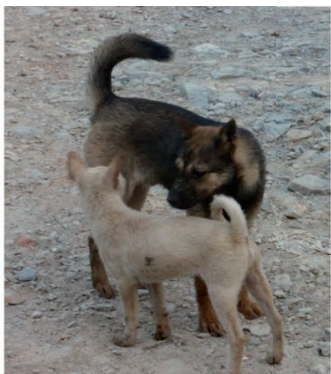

8. Contrasting color Guangxi/Guizhou (P. Touret)

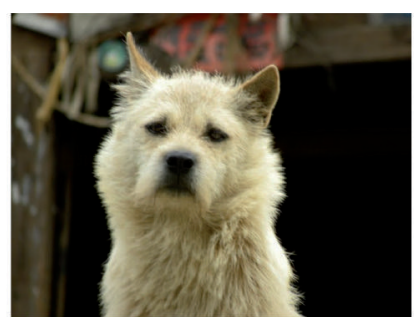

3. Light fawn Guangxi/Guizhou (Touret)

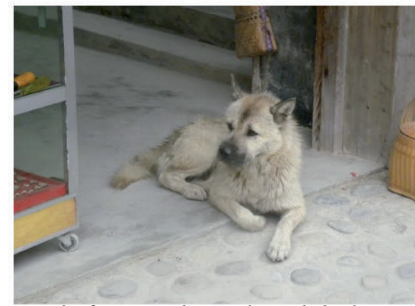

6. Pale fawn with mask and dark ears Guangxi/Guizhou (P. Touret)

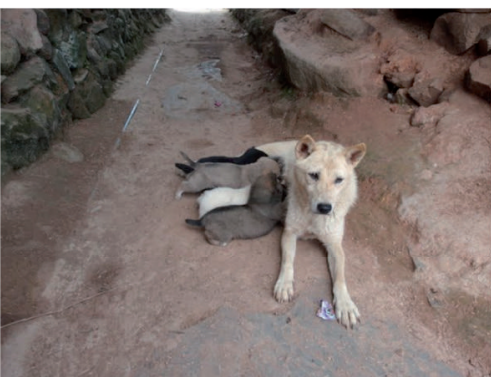

9. A litter of puppies showing various coat colors.

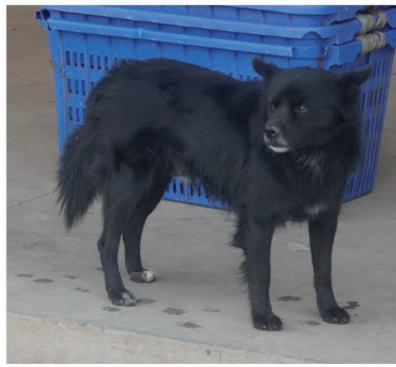

10. Black, Yunnan, (P. Touret)

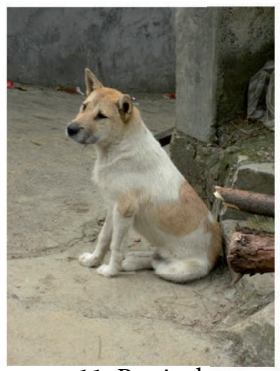

11. Particolor, Guangxi/Guizhou (J.-M. Touret)

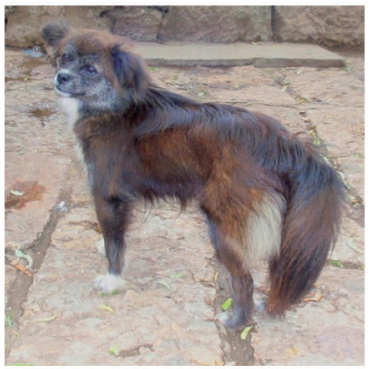

12. Yunnan, (P. Touret)

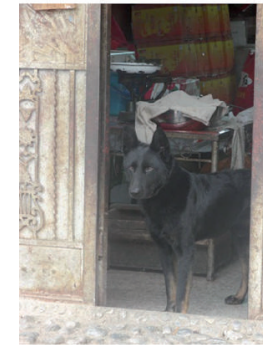

13. Black and tan, Yunnan

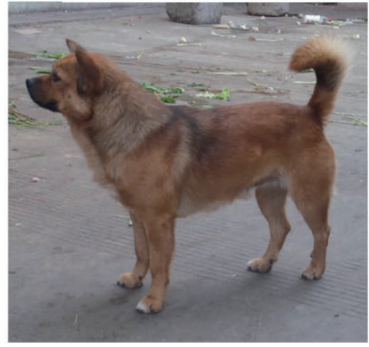

14. Darker and red fawn, Yunnan (P. Touret)

FIGURE 4: Variation in coat colors. 

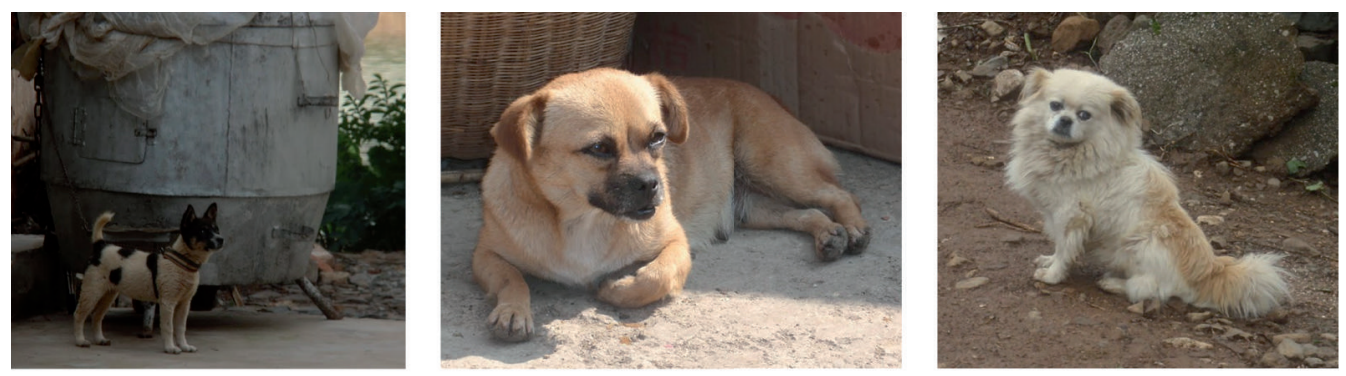

1. Small and 2-3 Basset type. Yunnan (P. Touret)

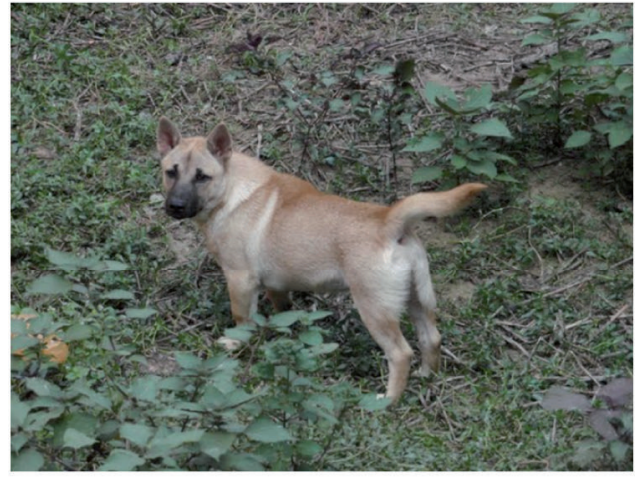

4. Short legged

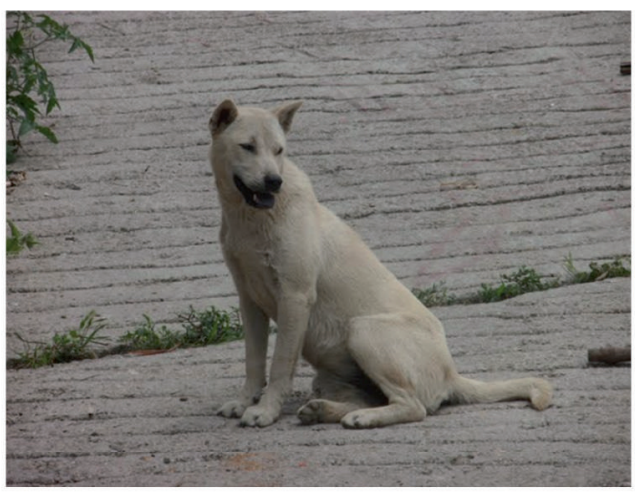

6. Long legged and substantial

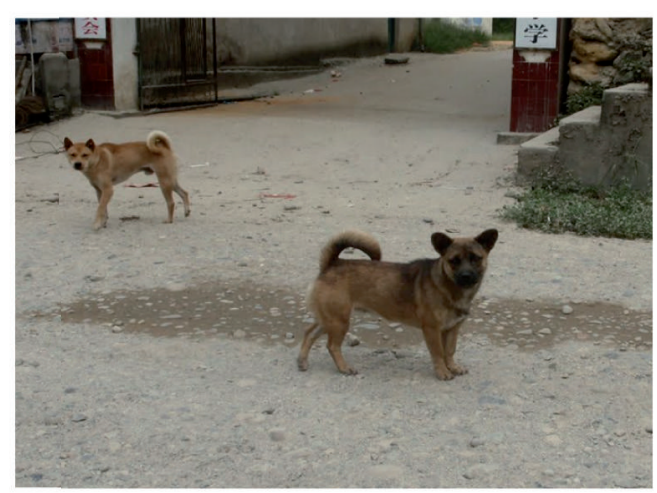

5. Medium to samll sized Guangxi/Guizhou (P. Touret)

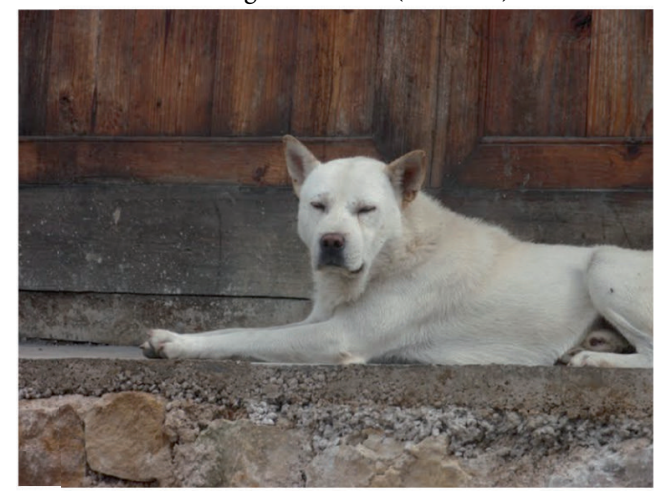

7. Powerful Guangxi/Guizhou (P. Touret)
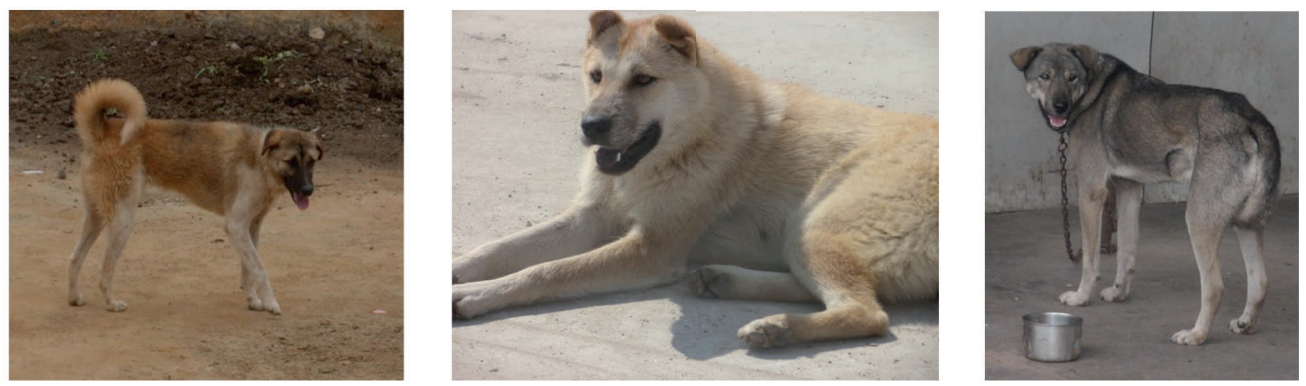

8, 9,and 10. Powerful. Left: Yunnans “Tu Gou," centre: Guangxi/Guizhou, and right: Yunnan (P. Touret)

Figure 5: Variation in structure and size.

\section{Discussion}

The documentation in this paper shows that a large proportion of the morphological features that are typically associated with the wide variety of Western dog breeds is present today among the dogs of rural southern China. It is unlikely that this richness of phenotypes would originate from a recent extensive crossbreeding to European dogs, the dogs featured here being traditionally bred in rural villages with no known influence of European breeds and therefore most probably indigenous to southern China. To definitely rule out crossbreeding with European dogs as the source 


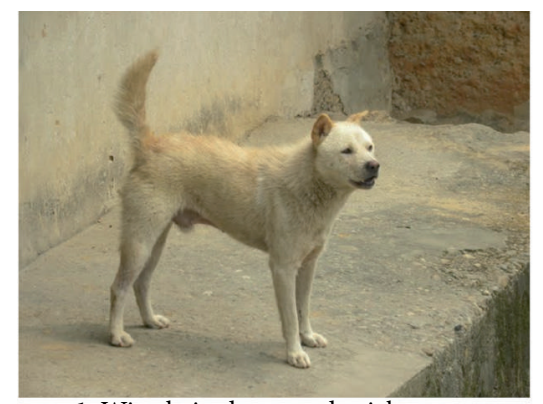

1. Wire-haired coat and prick ears

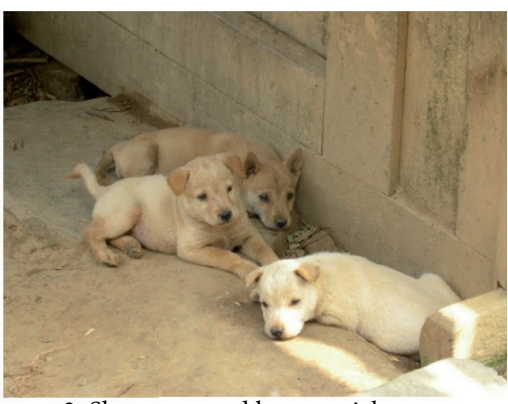

2. Short coat and lop or prick ears Guangxi/Guizhou (P. Touret)

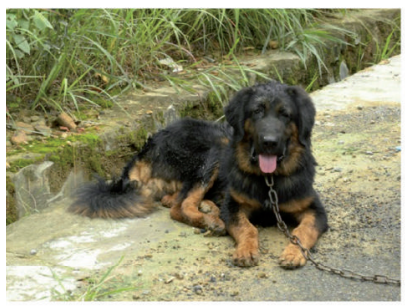

3. Black and tan, long hair on tail and lop ears

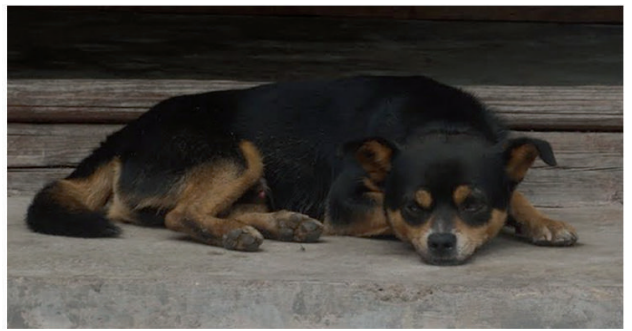

6. Half-erect ears

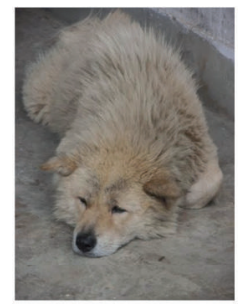

4. Long hair on body and prick ears

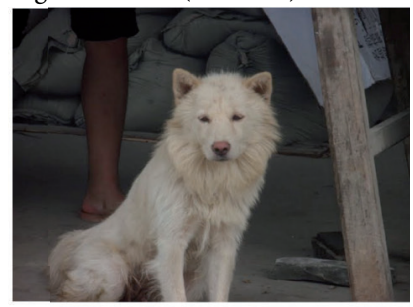

5. Mane and long-haired tail Guangxi/Guizhou (P. Touret)

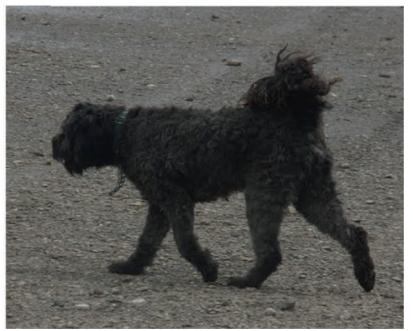

7. Curly coat, Yunnan (P. Touret)

FIGURE 6: Variation in hair length and texture and in ear sets.

of this phenotype diversity, analyses of autosomal DNA variation [16] must be carried out on these dogs.

Southern China's dogs harbor practically the full genetic diversity for mtDNA and Y-chromosome haplotypes while other dog populations harbor just a subset of the universal gene pool [1-3]. In other words, southern China's dogs have the richest genetic background among all dog populations worldwide, which might be expected to be reflected in a wide variety of phenotypes. Indeed, what might be conceived as the building blocks for much of the variation seen in today's "heavily selectively bred" European dogs are found, in line with this being the region where dogs first developed from Wolves.

There remains to explain the reasons for the homogenous looks of the Indian Pariah Dog, the Australian Dingo, and the New Guinea Singing Dog, which stand in stark contrast to the richness of phenotypes of the South Chinese dogs. The phenotypes of these three canine groups are popularly regarded as being the most primitive among dogs. On the other hand there is a contradiction in suggesting that the domestic dog physiognomy would have evolved from that of wolves, through the "poor" and uniform dingo/pariah phenotype in to the extremely diverse plethora of phenotypes in today's domestic dog population. In the case of the Dingo, analyses of mtDNA and Y-chromosomal DNA [12, 17,18 ] indicate an extreme population bottleneck at the forming of the Dingo population, offering an explanation for limited phenotype diversity. The mtDNA studies indicate that the Australian Dingo derive from East Asian dogs and not from the Indian Pariah Dog; a direct relation between the two populations does not seem to explain the similar morphologies. Possibly, the Dingo and Pariah phenotypes correspond with these populations generally being feral and therefore under similar natural selection. At any rate, the diverse phenotypes among dogs in southern China questions the popular notion that the earliest dogs were reddish, prickeared, bushy-tailed, medium-sized dogs.

\section{Acknowledgments}

The authors thank Philippe Touret and Jean-Maurice Touret for enabling us to use their photographs of Chinese dogs and the information pertaining to them, Yajnesh Shetty for the use of the Indian Pariah Dog photograph, and the photographers 


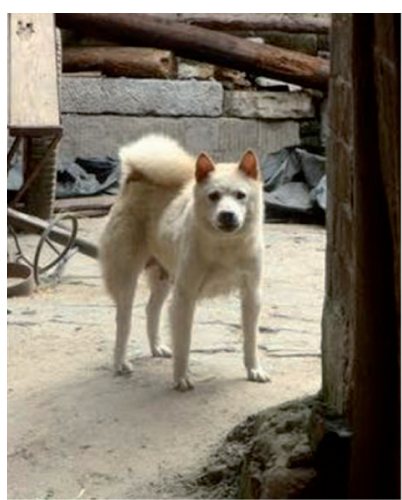

1. Curly tail

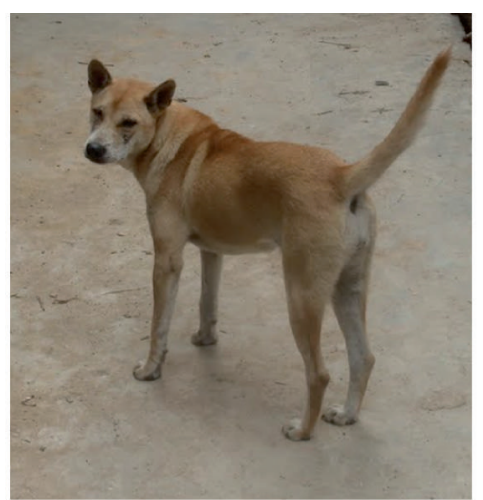

2. Long and straight tail carried high

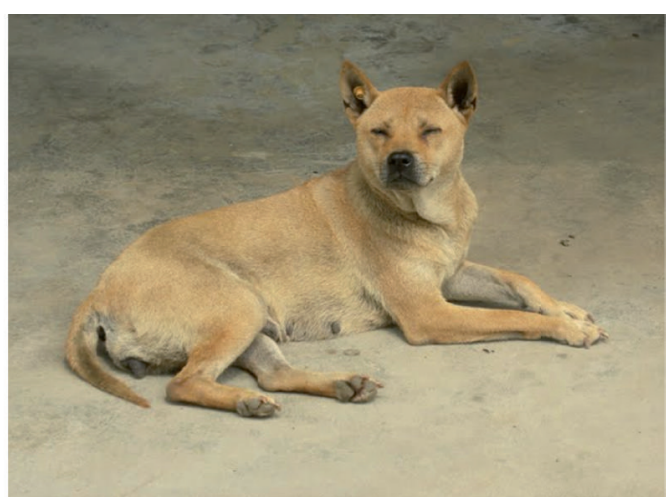

3. Short tail. Guangxi/Guizhou (P. Touret)

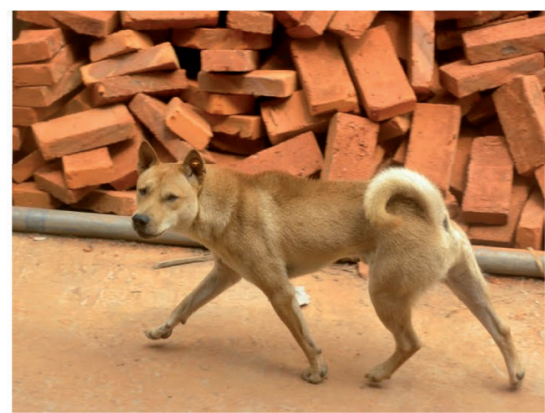

4. Curly tail on short coated dog

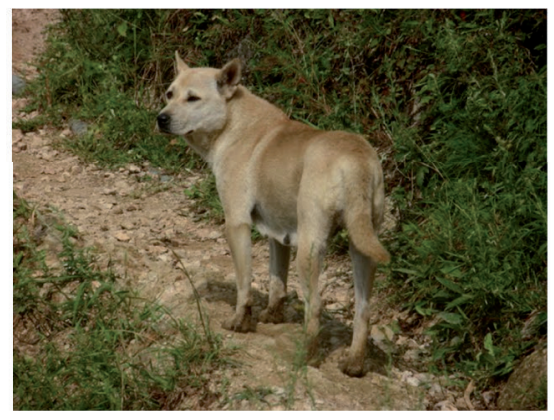

5. Bushy tail held low. Guangxi/Guizhou (P. Touret)

FIgURE 7: Variation in tail length and carriage.

who enable the use of their photographs through Wikimedia Commons. P. Savolainen is a Royal Swedish Academy of Sciences Research Fellow supported by a grant from the Knut and Alice Wallenberg Foundation.

\section{References}

[1] J. F. Pang, C. Kluetsch, X. J. Zou et al., "MtDNA data indicate a single origin for dogs south of yangtze river, less than 16,300 years ago, from numerous wolves," Molecular Biology and Evolution, vol. 26, no. 12, pp. 2849-2864, 2009.

[2] A. Ardalan, C. F. C. Kluetsch, A. B. Zhang et al., "Comprehensive study of mtDNA among Southwest Asian dogs contradicts independent domestication of wolf, but implies dog-wolf hybridization," Ecology and Evolution, vol. 1, no. 3, pp. 373-385, 2011.

[3] Z. L. Ding, M. Oskarsson, A. Ardalan et al., "Origins of domestic dog in Southern East Asia is supported by analysis of Ychromosome DNA," Heredity, vol. 108, no. 5, pp. 507-514, 2012.

[4] J. M. S. Davis and F. R. Valla, "Evidence for domestication of the dog 12,000 years ago in the Natufian of Israel," Nature, vol. 276, no. 5688 , pp. 608-610, 1978.

[5] T. Dayan, "Early domesticated dogs of the near east," Journal of Archaeological Science, vol. 21, no. 5, pp. 633-640, 1994.

[6] L. Chaix, "A preboreal dog from the northern Alps (Savoie, France)," in Dogs through Time: An Archaeological Perspective, S. J. Crockford, Ed., pp. 49-59, British Archaeological Reports, Oxford, UK, 2000.
[7] H. Napierala and H.-P. Uerpmann, "A "New" palaeolithic dog from central Europe," International Journal of Osteoarchaeology, vol. 22, no. 2, pp. 127-137, 2012.

[8] N. D. Ovodov, S. J. Crockford, Y. V. Kuzmin, T. F. G. Higham, G. W. L. Hodgins, and J. van der Plicht, "A 33,000-year-old incipient dog from the Altai Mountains of Siberia: evidence of the earliest domestication disrupted by the last Glacial Maximum," PLoS ONE, vol. 6, no. 7, Article ID e22821, 2011.

[9] B. M. Vonholdt, J. P. Pollinger, K. E. Lohmueller et al., "Genome-wide SNP and haplotype analyses reveal a rich history underlying dog domestication," Nature, vol. 464, no. 7290, pp. 898-902, 2010.

[10] C. F. C. Klütsch and M. D. C. de Caprona, "The IGF1 small dog haplotype is derived from Middle Eastern grey wolves: a closer look at statistics, sampling, and the alleged Middle Eastern origin of small dogs," BMC Biology, vol. 8, article 119, 2010.

[11] L. Corbett, The Dingo in Australia and Asia, University of New South Wales Press, Sydney, Australia, 1995.

[12] P. Savolainen, T. Leitner, A. N. Wilton, E. Matisoo-Smith, and J. Lundeberg, "A detailed picture of the origin of the Australian dingo, obtained from the study of mitochondrial DNA," Proceedings of the National Academy of Sciences of the United States of America, vol. 101, no. 33, pp. 12387-12390, 2004.

[13] J. Clutton-Brock, "Origins of the dog: domestication and early history," in The Domestic Dog, its Evolution, Behavior and Interactions with People, J. Serpell, Ed., pp. 7-20, Cambridge University Press, Cambridge, UK, 1995. 
[14] H. Hemmer, Domestication: The Decline of Environmental Appreciation, Cambridge University Press, Cambridge, UK, 1990.

[15] H. Epstein, Domestic Animals of China, Africana Publishing Company, New York, NY, USA, 1971.

[16] A. R. Boyko, R. H. Boyko, C. M. Boyko et al., "Complex population structure in African village dogs and its implications for inferring dog domestication history," Proceedings of the National Academy of Sciences of the United States of America, vol. 106, no. 33, pp. 13903-13908, 2009.

[17] M. C. R. Oskarsson, C. F. C. Klütsch, U. Boonyaprakob, A. Wilton, Y. Tanabe, and P. Savolainen, "Mitochondrial DNA data indicate an introduction through Mainland Southeast Asia for Australian dingoes and Polynesian domestic dogs," Proceedings of the Royal Society B, vol. 279, no. 1730, pp. 967-974, 2012.

[18] A. Ardalan, M. Oskarsson, C. Natanaelsson, A. N. Wilton, A. Ahmadian, and P. Savolainen, "Narrow genetic basis for the Australian dingo confirmed through analysis of paternal ancestry," Genetica, vol. 140, no. 1-3, pp. 65-73, 2012. 

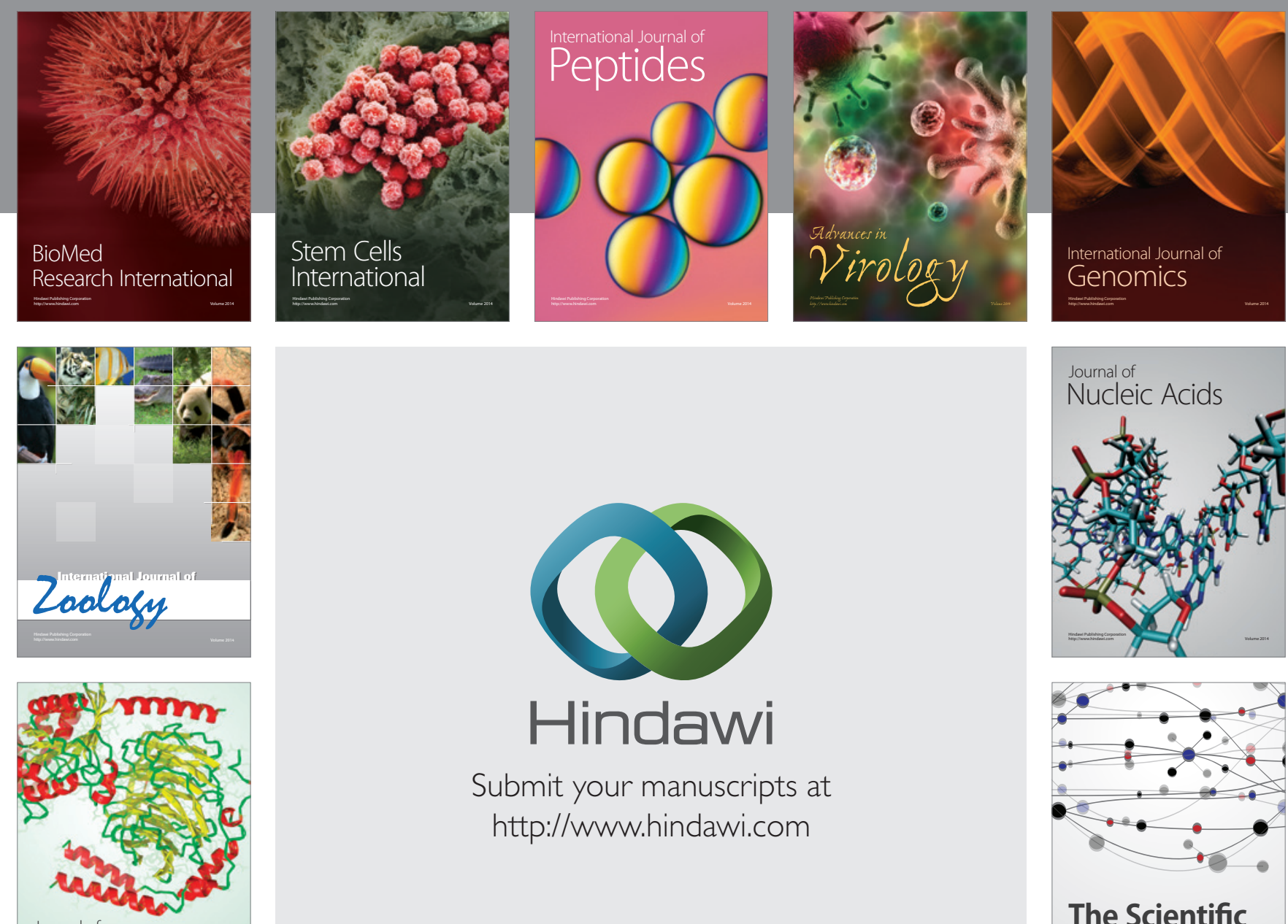

Submit your manuscripts at

http://www.hindawi.com

Journal of
Signal Transduction
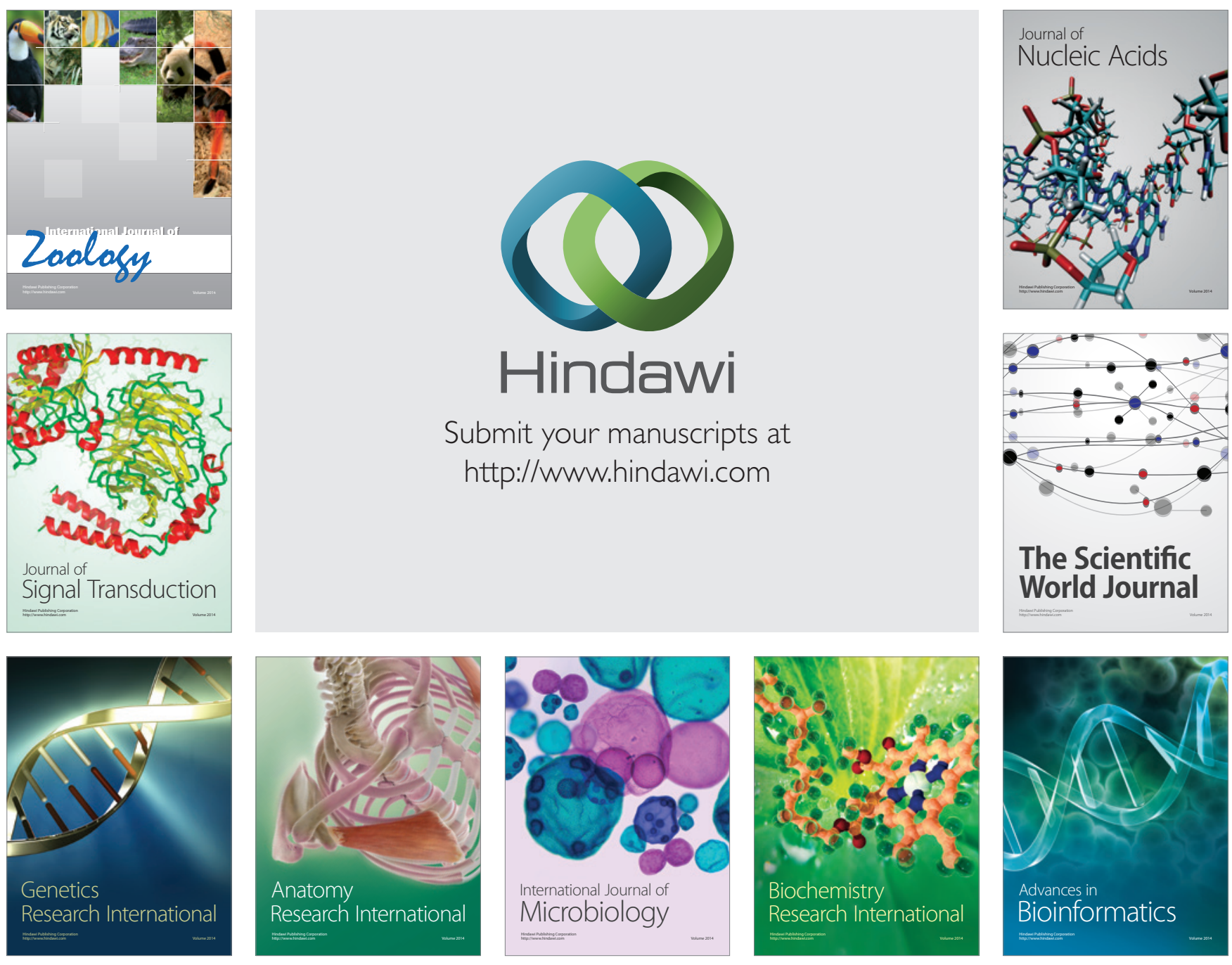

The Scientific World Journal
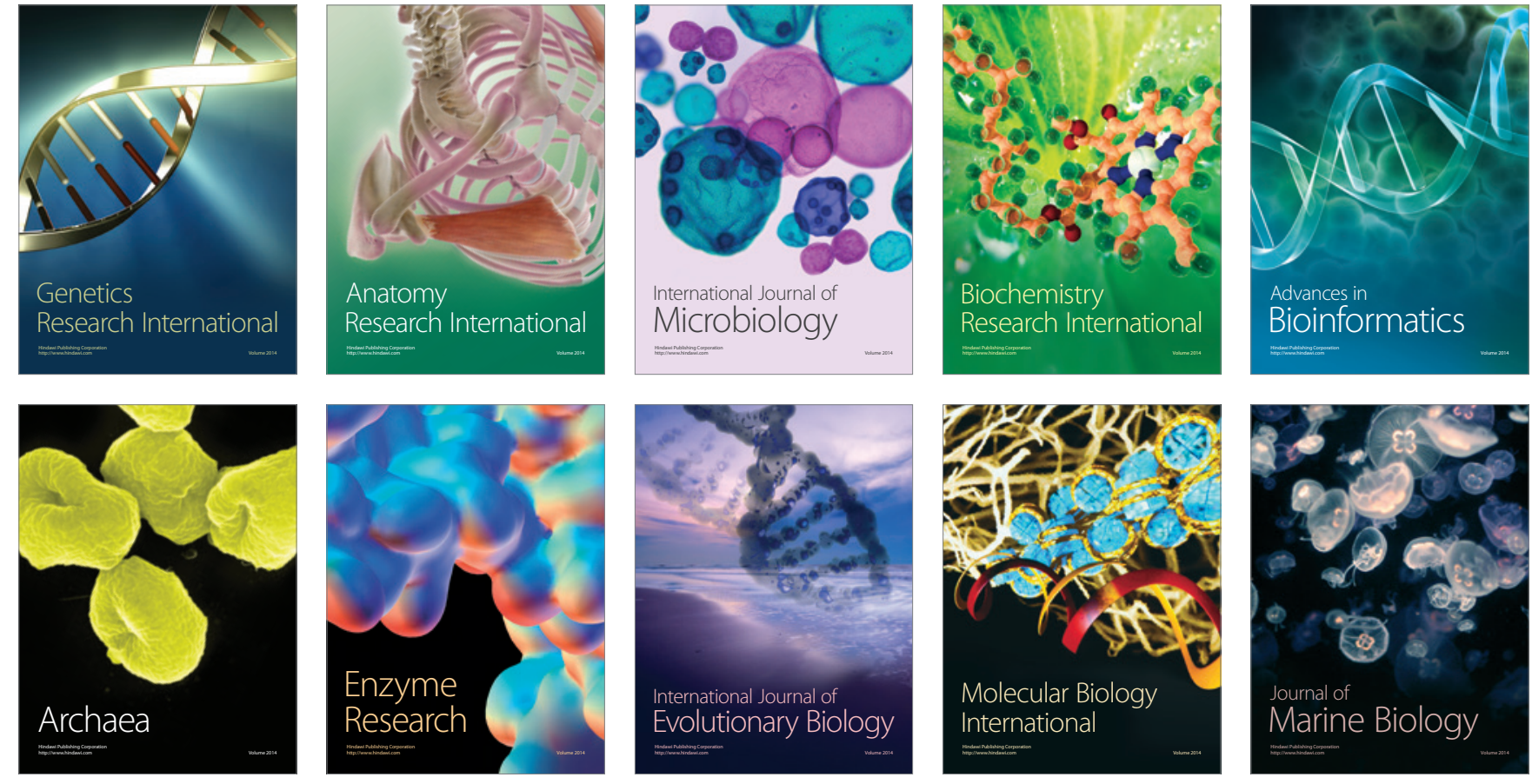